\title{
Whole-Cell Production of Patchouli Oil Sesquiterpenes in Escherichia coli: Metabolic Engineering and Fermentation Optimization in Solid-Liquid Phase Partitioning Cultivation
}

Francisco Aguilar, Kimia Ekramzadeh, Thomas Scheper, and Sascha Beutel*

Cite This: ACS Omega 2020, 5, 32436-32446

Read Online

ACCESS

Џlll Metrics \& More

回国 Article Recommendations

S1 Supporting Information

ABSTRACT: Patchouli oil is a major ingredient in perfumery, granting a dark-woody scent due to its main constituent (-)-patchoulol. The growing demand for patchouli oil has raised interest in the development of a biotechnological process to assure a reliable supply. Herein, we report the production of patchouli oil sesquiterpenes by metabolically engineered Escherichia coli strains, using solid-liquid phase partitioning cultivation. The (-)-patchoulol production was possible using the endogenous methylerythritol phosphate pathway and overexpressing a (-)-patchoulol synthase isoform from Pogostemon cablin but at low titers. To improve the (-)-patchoulol production, the exogenous mevalonate pathway was overexpressed in the multi-plasmid PTS + Mev strain, which increased the (-)-patchoulol titer 5-fold. Fermentation was improved further by evaluating several defined media, and optimizing the $\mathrm{pH}$ and temperature of culture broth, enhancing the (-)-patchoulol titer 3-fold. To augment the (-)-patchoulol recovery from fermentation, the solid-liquid phase partitioning

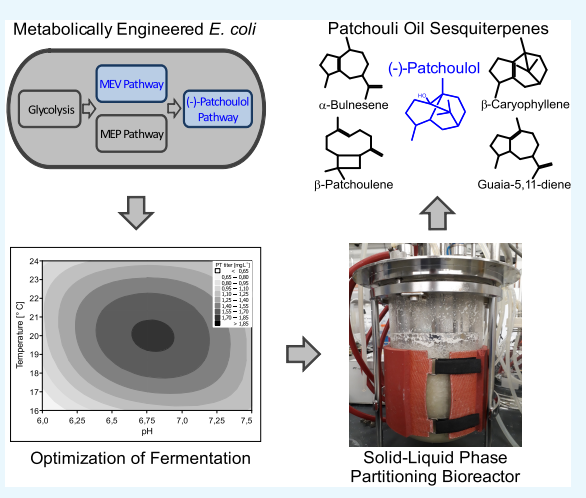
cultivation was analyzed by screening polymeric adsorbers, where the Diaion HP20 adsorber demonstrated the highest (-)-patchoulol recovery from all tests. Fermentation was scaled-up to fed-batch bioreactors, reaching a (-)-patchoulol titer of 40.2 $\mathrm{mg} \mathrm{L}^{-1}$ and productivity of $20.1 \mathrm{mg} \mathrm{L}^{-1} \mathrm{~d}^{-1}$. The terpene profile and aroma produced from the PTS + Mev strain were similar to the patchouli oil, comprising (-)-patchoulol as the main product, and $\alpha$-bulnesene, trans- $\beta$-caryophyllene, $\beta$-patchoulene, and guaia5,11 -diene as side products. This investigation represents the first study of (-)-patchoulol production in E. coli by solid-liquid phase partitioning cultivation, which provides new insights for the development of sustainable bioprocesses for the microbial production of fragrant terpenes.

\section{INTRODUCTION}

Essential oils have been used extensively as fragrant ingredients in the formulation of cosmetics due to their high content of aromatic terpenoids. Currently, the demand for cosmetic ingredients is growing with an estimated increase in the global market for 2022 of US $\$ 429.8$ billion. ${ }^{1}$ Moreover, $29 \%$ of the essential oil production is dedicated to aromatherapy, cosmetics, and fragrances, with an expected growth of US $\$ 27$ billion for $2022 .^{2}$ Among the diversity of cosmetic ingredients, the patchouli essential oil (PEO) from Pogostemon cablin Benth (Lamiaceae) is one of the most used essential oils, characterized by an earthy-woody aroma. ${ }^{3}$ The global market for 2018 was estimated to be US $\$ 67$ million $^{4}$ with a current price of US $\$ 65 / \mathrm{kg}^{5}$ and a calculated growth of $3.3 \%$ for 2025 . Actually, the main PEO producers are Indonesia, India, Malaysia, China, Singapore, Vietnam, and West Africa. ${ }^{6}$

PEO is used commonly as a base note in cosmetic formulations, which grants strong fixative properties, enhancing the fragrance endurance. ${ }^{7}$ Consequently, PEO has been used for the production of body lotions, soaps, detergents, and most importantly, perfumes. ${ }^{6}$ In addition, it has many applications due to its numerous biological activities that include antioxidant, antidepressant, anti-inflammatory, analgesic, cytotoxic, and antimicrobial activities. ${ }^{8}$

PEO is extracted from dried leaves of the perennial patchouli herb by steam distillation, which results in a recovery between 1.5 and $3.0 \% .^{9}$ Extraction of PEO by supercritical carbon dioxide can improve the extraction up to $5 \%$ with the advantage of avoiding compound degradation, delivering a superior oil quality. ${ }^{10}$ Its chemical composition is a rich mixture of more than 24 sesquiterpenes and its hydroxylated derivatives, in which the tricyclic (-)-patchoulol (patchouli alcohol) is the major compound, ${ }^{11}$ followed by the side products: $\alpha$-bulnesene, $\alpha$ - and $\beta$-patchoulene, $(E)-\beta$-caryophyllene, $\alpha$ - and $\beta$-guaiene, seychellene, aciphyllene, pogostone, and pogostol. ${ }^{11,12}$ The characteristic odor of PEO is determined mostly by (-)-patchoulol, but other hydrocarbons

Received: September 18, 2020

Accepted: November 25, 2020

Published: December 9, 2020 


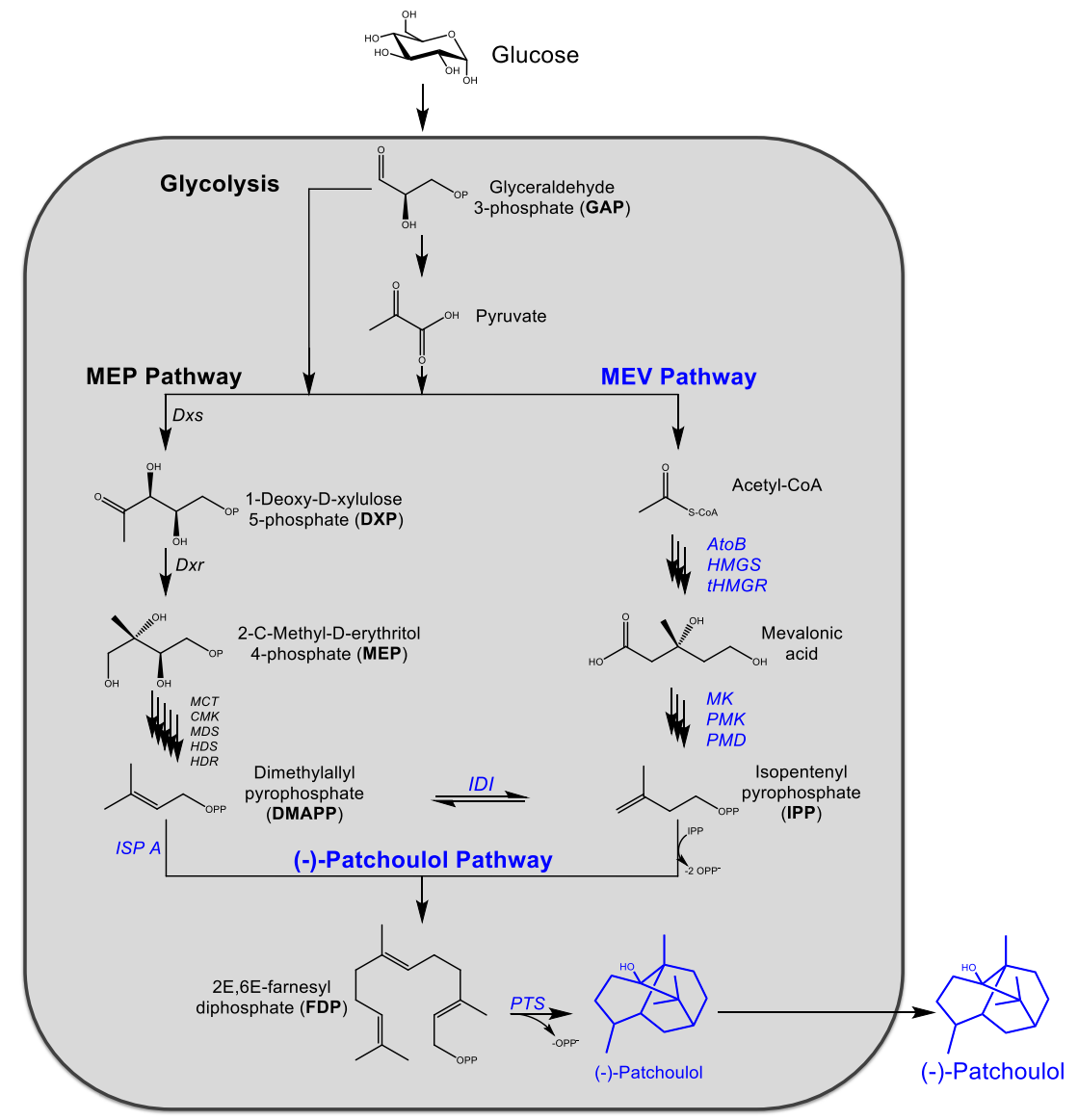

Figure 1. Engineering of the biosynthetic pathway for (-)-patchoulol production in E. coli. Heterologous genes appear in blue. Mevalonate (MEV) pathway genes: Acetyl-CoA acetyltransferase (AtoB), HMG-CoA synthase (HMGS), truncated HMG-CoA reductase (tHMGR), mevalonate kinase $(M K)$, phosphomevalonate kinase $(P M K)$, mevalonate diphosphate decarboxylase $(P M D)$, isoprenyl diphosphate isomerase (IDI), and farnesyl diphosphate synthase (ISPA). (-)-Patchoulol pathway: (-)-patchoulol synthase isoform (PTS).

contribute to the overall fragrance such as the patchoulenes and guaienes. ${ }^{3,13}$ Like most of the essential oils, PEO demonstrates variations in the chemical composition according to the geographical region of cultivation, harvest time, and genotypes. ${ }^{6,14}$ In consequence, two distinct chemotypes have been identified: the (-)-patchoulol type and pogostone type on plantations of South China. ${ }^{14}$

Biosynthesis of PEO terpenoids follows the common metabolic pathway of plant sesquiterpenes, initiating from the carbon metabolism, which leads to the formation of pyruvate and glyceraldehyde 3 -phosphate. ${ }^{15}$ In the plastidial methylerythritol phosphate pathway (MEP), both molecules are condensed, yielding 1-deoxy-D-xylulose 5-phosphate (DXP), which undergoes an enzymatic cascade to form (E)4-hydroxy-3-methylbut-2-enyl pyrophosphate (HMB-PP). ${ }^{16}$ In parallel, acetyl coenzyme $\mathrm{A}$ is processed through distinct enzymatic bioconversions by the cytoplasmic mevalonate pathway (MEV), yielding mevalonate 5-diphosphate (Mev$\mathrm{PP}) .{ }^{17}$ Both pathways converge resulting in the formation of the isomers isopentenyl diphosphate (IPP) and dimethyl diphosphate (DMAPP). ${ }^{15}$ After condensation of one unit of IPP and two units of DMAPP, the sesquiterpene precursor farnesyl diphosphate (FDP) is formed. ${ }^{18}$ The substrate is catalyzed by the (-)-patchoulol synthase, a promiscuous terpene synthase that allows the formation of the derived sesquiterpenes contained in PEO, including the hydroxylatedsesquiterpene $(-)$-patchoulol as the main product. ${ }^{19}$
An important step in the study of the (-)-patchoulol biosynthesis was the functional expression and characterization of the native (-)-patchoulol synthase from $P$. cablin, in which (-)-patchoulol was produced as the major compound via in vitro biotransformation reactions, followed by 13 other sesquiterpenes. ${ }^{19}$ In addition, our research group characterized a (-)-patchoulol synthase isoform from P. cablin with a total of 19 residue substitutions in the active site that yielded germacrene $\mathrm{A}$ and $(-)$-patchoulol as the major products. ${ }^{20}$

The metabolic engineering for the whole-cell production of (-)-patchoulol has been reported in yeast, ${ }^{21,22}$ algae, ${ }^{23}$ and Cornybacterium glutamicum bacteria. ${ }^{24}$ Additionally, Firmenich has reported the production of a soft version of patchouli that lacks the leathery-woody notes, using engineered yeast. ${ }^{25}$ All of the after-mentioned microbial platforms include distinct biosynthetic pathways that compete for the precursor FDP, such as the ergosterol and carotenoid pathways. Consequently, the metabolic engineering for (-)-patchoulol is challenging in these hosts and it requires the knockdown of the competing pathways to obtain feasible (-)-patchoulol levels. ${ }^{26}$ Conversely, the engineering of the $(-)$-patchoulol pathway in Escherichia coli can overcome these shortcomings, since E. coli does not comprise such competing pathways and it can maximize the catalyzation of FDP for (-)-patchoulol production. ${ }^{25,27}$ Besides, E. coli comprises many advantages such as a well-known cell metabolism, vast E. coli-based 

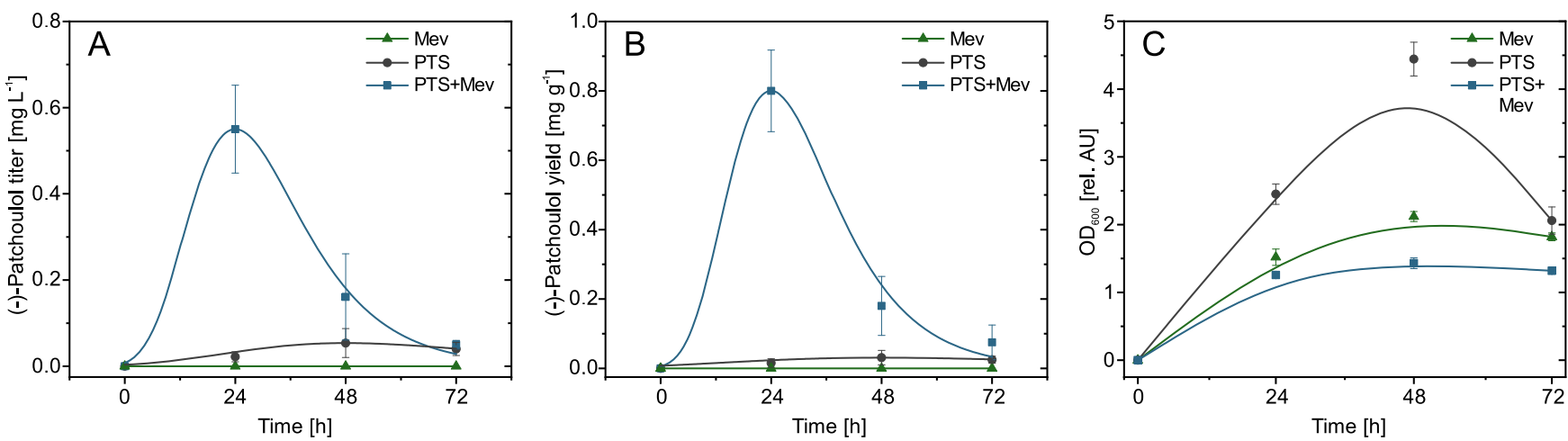

Figure 2. Production of (-)-patchoulol and growth kinetics from the Mev, PTS, and PTS + Mev E. coli strains during $72 \mathrm{~h}$ of cultivation. (A) (-)-Patchoulol titer and (B) (-)-patchoulol yield, $\mathrm{Y}_{\mathrm{P} / \mathrm{X}}$. (C) Cell growth shown by the optical density $\left(\mathrm{OD}_{600}\right)$. Plots correspond to the mean of three independent tests with standard deviation $(\mathrm{SD})$ error bars.

expression vectors, and the capability to reach high-cell-density cultures by fed-batch fermentation. ${ }^{27,28}$

Additionally, the recovery of sesquiterpenes is also challenging during fermentation due to cell toxicity and loss of products by volatilization. ${ }^{29}$ To circumvent these issues, the in situ product recovery method has been applied during fermentation to trap the terpenes into an extractant. Such a method can be implemented by liquid-liquid phase partitioning cultivation (LLPPC) with liquid extractants (liquid polymers and organic solvents) or by solid-liquid phase partitioning cultivation (SLPPC) with solid extractants (charcoal, zeolites, and polymeric adsorbers). ${ }^{30}$

In this study, we report the metabolic engineering of $E$. coli for the whole-cell production of (-)-patchoulol. For that, multi-plasmid E. coli strains were constructed with the exogenous MEV pathway and a (-)-patchoulol synthase isoform from $P$. cablin. Furthermore, fermentation was enhanced at shake flask scale by evaluating defined media, and optimizing temperature and $\mathrm{pH}$ through a factorial design. To improve the recovery of $(-)$-patchoulol during fermentation, the in situ recovery of (-)-patchoulol was analyzed by SLPPC with polymeric adsorbers. Moreover, the fermentation was scaled-up to fed-batch bioreactors to improve (-)-patchoulol productivity.

\section{RESULTS AND DISCUSSION}

2.1. Engineering the Metabolic Pathway of Terpenes. The design of the metabolic pathway was constructed in E. coli strains to convert simple sugars (e.g., D-glucose) to the fragrant sesquiterpenes from the patchouli oil, focusing mainly in (-)-patchoulol, as depicted in Figure 1. The metabolic engineering comprised the heterologous MEV pathway by the pBbA5c-MevT(CO)-MBIS (CO, ispA) plasmid (pMev), which consisted of 8 genes controlled by the lacUV5 promoter. $^{31}$ The acetyl-CoA from the glycolysis cycle was catalyzed by acetyl-CoA acetyltransferase (AtoB), HMG-CoA synthase (HMGS), and truncated HMG-CoA reductase ( $t H M G R$ ) from the bottom MEV operon, resulting in the formation of mevalonate. This intermediate was processed through an enzymatic reaction cascade by the enzymes from the upper MEV operon (mevalonate kinase $(M K)$, phosphomevalonate kinase $(P M K)$, and mevalonate diphosphate decarboxylase $(P M D))$, forming the substrate isoprenyl pyrophosphate. The latter underwent isomerization by isoprenyl diphosphate isomerase (IDI) and further condensation by farnesyl diphosphate synthase (ISPA), leading to the precursor FDP. ${ }^{31}$ Finally, this precursor was catalyzed by the (-)-patchoulol synthase, which is the critical enzyme in the (-)-patchoulol biosynthesis. For that, a recombinant (-)-patchoulol synthase isoform was used, containing 19 residue substitutions, developed in our previous study. ${ }^{20}$

To analyze the (-)-patchoulol production in whole-cell systems, distinct E. coli BL21(DE3) strains were developed: Mev strain (MEV pathway plasmid) as a negative control, PTS strain ((-)-patchoulol synthase isoform plasmid), and PTS + Mev strain (both plasmids). The latter strain was engineered as a multi-plasmid strain due to the advantages in terms of terpene production over single polycistronic plasmid strains, as demonstrated in our previous report. ${ }^{32}$ Cultivation tests were run in shake flasks and monitored during $72 \mathrm{~h}$ with an organic solvent overlay to trap the terpenes and prevent their volatilization. As expected, the negative control did not produce (-)-patchoulol or any other patchouli oil terpenes but yielded small amounts of farnesol. This suggests that the excess of FDP due to the overexpression of the MEV pathway was hydrolyzed by endogenous phosphatases as an internal mechanism of E. coli to detoxify the FDP pool, as explained by other studies. $^{33,34}$

On the other hand, the PTS strain was able to produce small amounts of (-)-patchoulol, using the native FDP pool derived from the endogenous MEP pathway (Figure 2). In addition, the PTS strain produced higher amounts of soluble (-)-patchoulol synthase protein than the PTS + Mev strain (Figure S1). This suggests an imbalance in the metabolic flux toward (-)-patchoulol from the PTS strain, where the native supply of FDP was the limiting factor because it is required by E. coli for the biosynthesis of peptidoglycans in the cell wall ${ }^{35}$ and isoprenoid quinones for the respiratory metabolism. ${ }^{36}$ To improve the FDP supply, we constructed the PTS + Mev strain, which overexpresses the MEV pathway and the (-)-patchoulol synthase. As a result, the (-)-patchoulol production improved significantly, augmenting the (-)-patchoulol titer 5-fold and the product yield 8-fold when compared to those of the PTS strain.

The overexpression of the MEV pathway decreased the cell growth, as demonstrated for the reduced optical density from the Mev and PTS + Mev strains (Figure 2c). This suggests a strong metabolic burden when overexpressing the MEV pathway and even more in combination with $(-)$-patchoulol synthase. Such growth reduction has also been observed due to the overexpression of the MEV pathway in other metabolically engineered $E$. coli strains for the production of the 

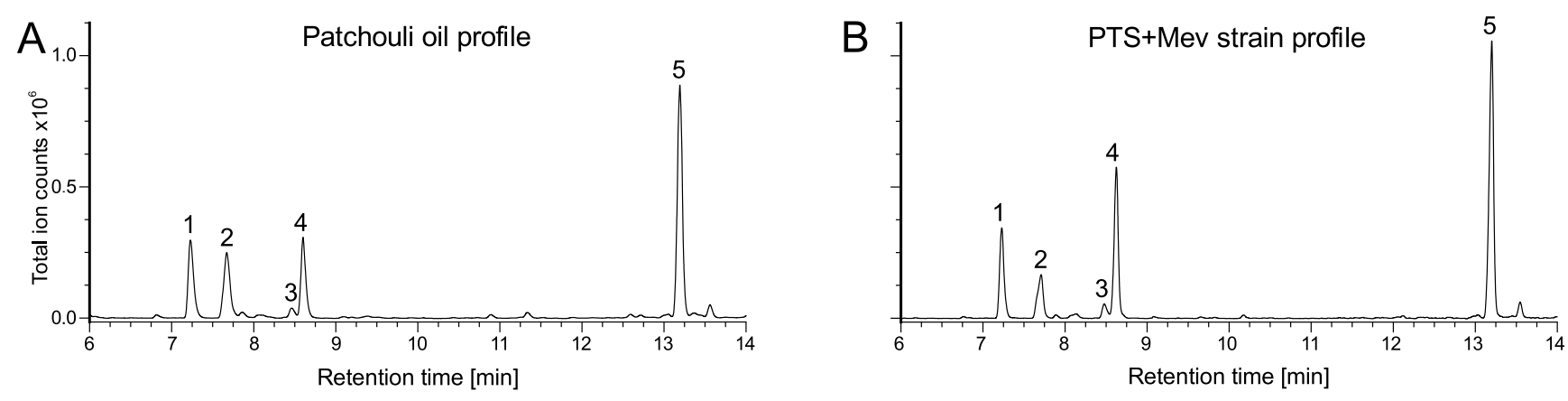

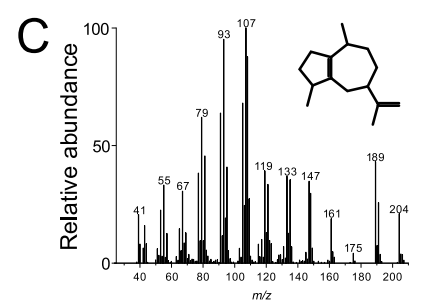

1. $\alpha$-Bulnesene (RI: 1613)

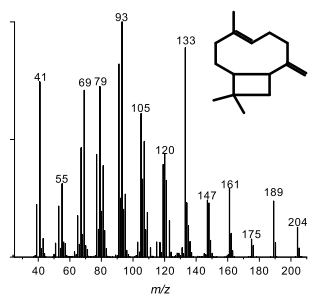

2. trans- $\beta$-Caryophyllene (RI: 1607)

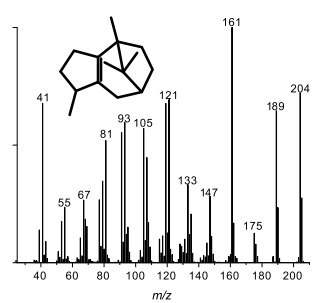

3. $\beta$-Patchoulene

(RI: 1519)

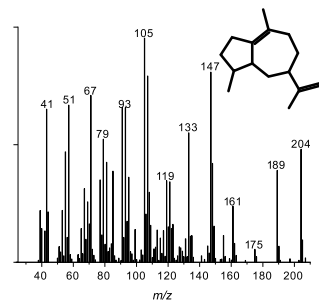

4. Guaia-5,11-diene (RI: 1649)

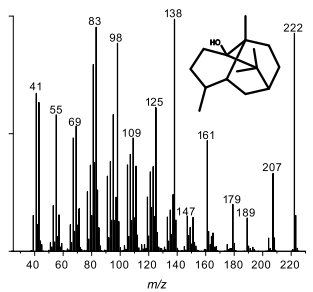

5. (-)-Patchoulol (RI: 2155)

Figure 3. Gas chromatography-mass spectrometry (GC-MS) chromatograph comparing the terpene profile between the patchouli oil (A) and the PTS + Mev E. coli strain (B). (C) Mass spectra from identified terpenes from PTS + Mev E. coli strain. A full comparison of the mass spectra of terpene products between the patchouli oil and the PTS + Mev strain is found in Table S2.
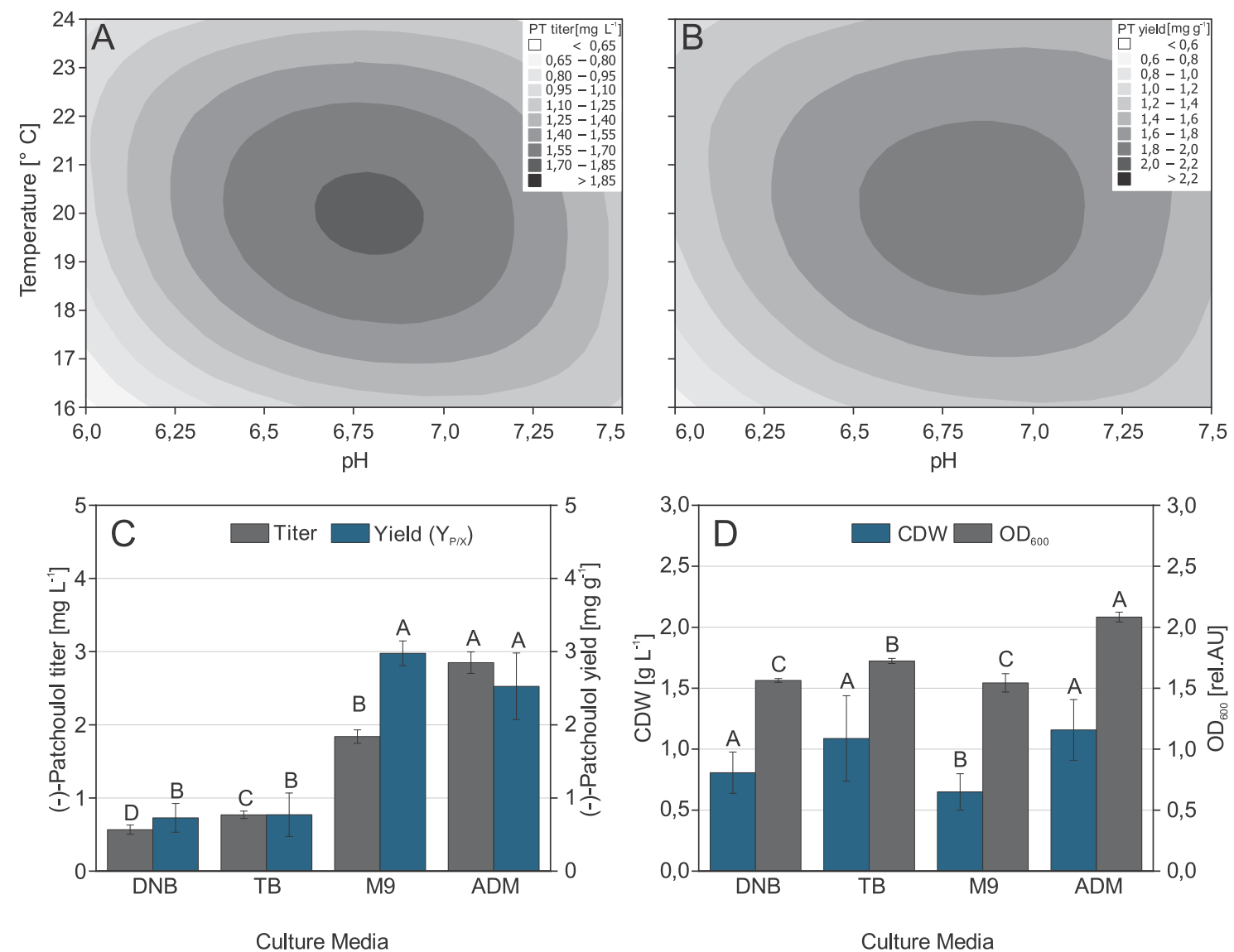

Figure 4. Optimization of cultivation conditions for the whole-cell production of $(-)$-patchoulol. Factorial design of the temperature and $\mathrm{pH}$ in culture media: (A) (-)-Patchoulol titer and (B) (-)-patchoulol yield, $\mathrm{Y}_{\mathrm{P} / \mathrm{X}}$. Evaluation of defined media: (C) (-)-Patchoulol titer and yield $\mathrm{Y}_{\mathrm{P} / \mathrm{X}}$. (D) Growth kinetics described by the cell dry weight $(\mathrm{CDW})$ and optical density $\left(\mathrm{OD}_{600}\right)$. PT: $(-)$-patchoulol. Data are the mean of three independent tests with SD error bars and analyzed by analysis of variance (ANOVA) $(\alpha=0.05)$. Letters that differ are significantly different.

sesquiterpenes valerenadiene and khusimene. ${ }^{32,37}$ Thus, this is the result of energy consumption for protein synthesis during the overexpression of multiple genes; ${ }^{28}$ in this case, nine heterologous genes. 
2.2. Comparison of the Terpene Profile. The PTS + $\mathrm{Mev}$ strain produced a similar terpene profile when compared to the naturally occurring patchouli oil from Indonesia, producing as major product (-)-patchoulol and as side products guaia-5,11-diene, $\alpha$-bulnesene, trans- $\beta$-caryophyllene, and $\beta$-patchoulene (Figure 3 ). Interestingly, both terpene profiles were similar in terms of the product ratio, except for the higher levels of guaia-5,11-diene and the lower content of trans- $\beta$-caryophyllene from the PTS + Mev strain when compared to that of the patchouli oil. Moreover, the product profile from the PTS + Mev strain was also similar to other reported profiles from Indonesian patchouli oils, which reported (-)-patchoulol as the major product and $\alpha$ - and $\beta$ patchoulene, $\beta$-caryophyllene, guaia-5,11-diene, $\alpha$-gurjunene, and seychellene as side products. ${ }^{38,39}$ The terpene profile from the PTS + Mev strain was similar to that of other metabolically engineered yeasts, ${ }^{21}$ with the difference in the higher content of guaia-5,11-diene and the less content of $\alpha$-bulnesene than those of the other yeast platforms.

2.3. Optimization of Cultivation Conditions. 2.3.1. Optimization of the Cultivation Temperature and $\mathrm{pH}$. Cultivation conditions are relevant factors towards the improvement of terpene productivity and therefore, they were analyzed with the best performing E. coli strain (PTS + $\mathrm{Mev})$. Thus, a factorial design $\left(2^{2}\right)$ was carried out to optimize the temperature and $\mathrm{pH}$ of the cultivation at shake flask scale with M9 medium ( $5 \mathrm{~g} \mathrm{~L}^{-1}$ glucose). Production cultures were induced according to the previous section with $0.5 \mathrm{mM}$ IPTG, which showed the highest (-)-patchoulol levels than all of the other induction tests (Figure S2).

As observed in Figure 4a.b, both the (-)-patchoulol titer and yield demonstrated a similar behavior, where optimal conditions were found at $20{ }^{\circ} \mathrm{C}$ and $\mathrm{pH} 6.75$, improving the (-)-patchoulol titer and yield 3-fold higher than the previous cultivation $\left(24{ }^{\circ} \mathrm{C}\right.$ and $\left.\mathrm{pH} 7.5\right)$. The (-)-patchoulol titer was affected more by temperature than $\mathrm{pH}$, showing an optimal temperature between $19-21{ }^{\circ} \mathrm{C}$ for the (-)-patchoulol titer and $18-22{ }^{\circ} \mathrm{C}$ for the (-)-patchoulol yield (Figure 4a). Temperature plays an important role in cell metabolism and is directly proportional to the protein synthesis rate. ${ }^{40}$ Commonly, plant terpene synthases expressed in E. coli require low protein synthesis rates to allow proper folding of the protein. ${ }^{41}$ Such behavior was confirmed in our results, where tests carried out at lower temperatures produced higher amounts of soluble (-)-patchoulol synthase protein and reduced inclusion bodies when compared to those of tests cultivated at higher temperatures (Figure S3).

Nevertheless, the lowest temperature tests did not produce the highest (-)-patchoulol titers; possibly, due to the diminished enzyme activity of the (-)-patchoulol synthase. This could be supported because in previous in vitro biotransformation reactions, ${ }^{42}(-)$-patchoulol synthase showed higher activity at higher temperatures, reaching its maximum at $34{ }^{\circ} \mathrm{C}$. Therefore, a balance is required among the production of soluble (-)-patchoulol synthase protein, enzyme activity, and cell growth, as observed in the tests grown at 20 ${ }^{\circ} \mathrm{C}$, which achieved the highest (-)-patchoulol production. Similarly, the optimal induction temperature was found at 20 ${ }^{\circ} \mathrm{C}$ for the production of $\alpha$-humulene and khusimene in $E$. coli platforms in both shake flasks and bioreactors. ${ }^{43,44}$ Besides, such temperature could be a contributing factor to reduce the volatilization of terpenes in bioreactors.
The optimal $\mathrm{pH}$ was observed between $\mathrm{pH}$ 6.6-6.9 ((-)-patchoulol titer) and $\mathrm{pH}$ 6.5-7.1 ((-)-patchoulol yield), in which lower $\mathrm{pH}$ values disfavored (-)-patchoulol production (Figure $4 \mathrm{~b}$ ). Such a result could be explained because $\mathrm{pH}$ reduction can inhibit the expression of heterologous proteins in E. coli, where amino acid decarboxylases are induced to export amines and counteract acidification. ${ }^{45}$ In this way, E. coli can maintain $\mathrm{pH}$ homeostasis in the range of $\mathrm{pH} 7.2-7.8$ in the cytoplasm. ${ }^{46}$ The in vivo optimal $\mathrm{pH}$ (found here) is similar to that of the in vitro biotransformation reactions, determined between $\mathrm{pH}$ 6.46.6. ${ }^{42}$ Accordingly, our results are similar to the E. coli strains used for the production of longifolene ${ }^{47}$ and sclareol, ${ }^{48}$ which used a $\mathrm{pH}$ of 7.0 during cultivation. Thereafter, the cultivation conditions of $20{ }^{\circ} \mathrm{C}$ and $\mathrm{pH} 6.75$ were used for further evaluations.

2.3.2. Evaluation of Culture Media. During terpene overexpression in bacterial production strains, the culture media is critical to modulate the correct supply of compounds for protein synthesis. To analyze this factor, distinct defined media (M9, DNB, and ADM with $5 \mathrm{~g} \mathrm{~L}^{-1}$ glucose) were tested due to their suitability for fed-batch cultivation by supplying limited carbon levels. Additionally, the terrific broth (TB) broth was tested to compare the (-)-patchoulol production between complex and defined media. Accordingly, the highest (-)-patchoulol titer was observed in the ADM test, followed by the M9, TB, and DNB tests (Figure $4 \mathrm{c}$ ). The ADM test augmented the $(-)$-patchoulol titer 1.5 -fold when compared to the medium used in the previous section (M9), with a similar (-)-patchoulol yield. Cell growth was also higher in the ADM test and in the TB broth (Figure 4d), which is known to promote biomass production. The lowest cell growth was observed in the M9 test, which was expected due to the low amounts of nitrogen, magnesium, and trace elements.

The $\mathrm{ADM}^{32}$ is used for the in vivo production of sesquiterpenes as a modified version of the "medium C" used for the production of colominic acid in the E. coli K-235 strain. ${ }^{49}$ On the other hand, M9 is a minimal growth medium for Enterobacteria ${ }^{50}$ and used successfully for the in vivo production of 5 -epi-aristolochene, $(+)$ - $\delta$-cadinene, and vetispiradiene. ${ }^{51}$ Both media are very similar in their composition but mainly differ in the nitrogen content, where ADM contains 20 -fold more than M9. Interestingly, the ADM test produced the highest amount of soluble $(-)$-patchoulol synthase protein of all tested media (Figure S4). The most used media for terpene production in $E$. coli comprise complex media $\left(\mathrm{LB},{ }^{37,52}\right.$ $2 \mathrm{YT}^{33}$ and $\mathrm{TB}^{53,54}$ ) and defined media (AM, ${ }^{48}$ EZ-Rich, ${ }^{55,56}$ and $\left.\mathrm{M}^{47,51,57}\right)$. Interestingly, the ADM medium contains the highest amount of inorganic nitrogen than all of the aftermentioned media. Apparently, nitrogen levels point to be a critical factor for (-)-patchoulol production and could be explained because nitrogen is required for the cell growth and synthesis of amino acids during protein expression. ${ }^{58,59}$ Hence, more testing is required to optimize the nitrogen levels and rule out other media constituents, which could affect the (-)-patchoulol production.

2.4. Evaluation of SLPPC by Polymeric Solid Adsorbers. The recovery of fragrant sesquiterpenes from fermentation is challenging due to their hydrophobicity and volatility. ${ }^{29}$ Such physicochemical properties can result in cell toxicity and product loss by volatilization, reducing significantly the terpene production. Although the application of fedbatch fermentation can improve product productivity, the 

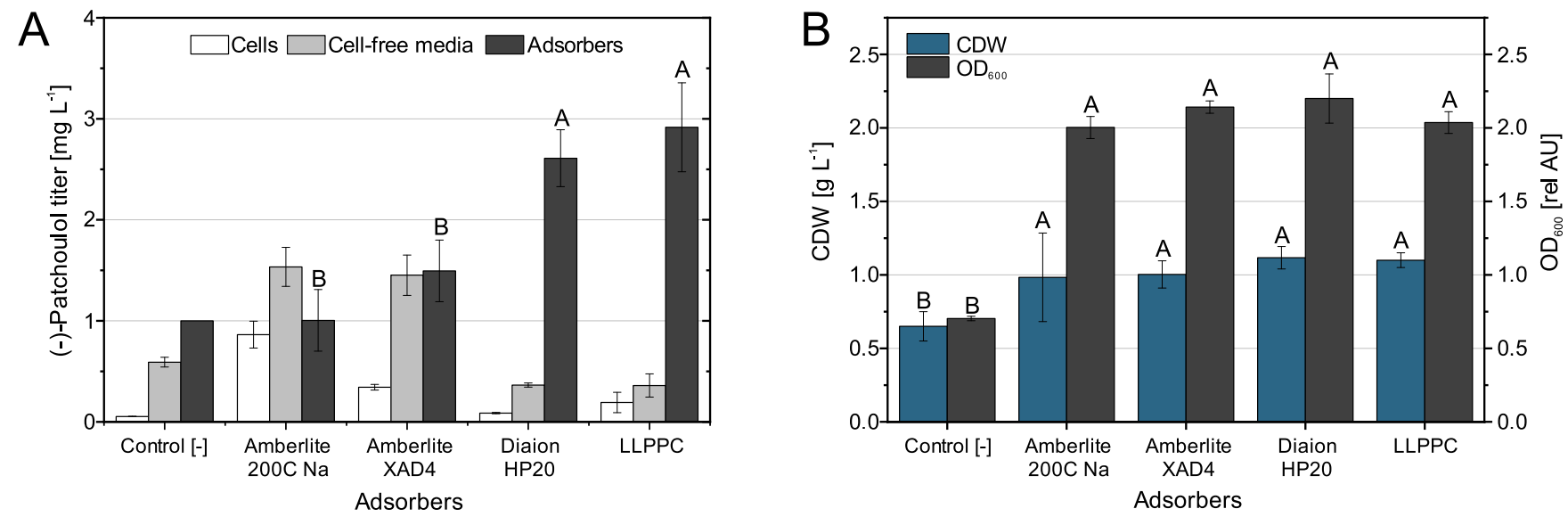

Figure 5. Comparison of the (-)-patchoulol recovery from different polymeric adsorbers. (A) (-)-Patchoulol titer recovered from adsorbers, cellfree media, and cells. (B) Growth kinetics described by the cell dry weight $(\mathrm{CDW})$ and optical density $\left(\mathrm{OD}_{600}\right)$. Control $(-)$ test without extractants. Liquid-liquid phase partitioning cultivation (LLPPC) test with an organic solvent overlay. Data are the mean of three independent tests with SD error bars. Data analyzed by ANOVA $(\alpha=0.05)$. Letters that differ are significantly different.

terpene recovery can be reduced drastically due to the prolonged time of cultivation. ${ }^{29}$

To avoid product loss, the SLPPC method was evaluated by testing solid adsorbers, which were selected according to their physical properties (pore radius, surface area, and particle size). Accordingly, different cross-linked polystyrene divinylbenzene adsorbers were analyzed by an in vivo SLPPC test, similar to Halka. ${ }^{60}$ An organic solvent test was also included to compare the trapping performance between LLPPC and SLPPC, and a test without extractants was carried out as a negative control.

The highest ( - -patchoulol levels from all adsorber tests were observed by the Diaion HP20 test, reaching a (-)-patchoulol titer of $2.3 \mathrm{mg} \mathrm{L}^{-1}$ (Figure 5a). Moreover, the Diaion HP20 test reached the highest (-)-patchoulol recovery ratio among all of the adsorbers (85.3\% adsorber, $11.9 \%$ cell-free media, and $2.8 \%$ cell fractions), followed by Amberlite XAD4 and Amberlite 200C (Table 1). Surprisingly,

Table 1. Recovery Ratio of (-)-Patchoulol (\%) from the Adsorber, Organic Solvent, Cell-Free Media, and Cell Fractions from Cultivation Tests with the PTS + Mev E. coli Strain, Loaded with Different Polymeric Adsorbers ${ }^{b}$

\begin{tabular}{lcccc}
\multicolumn{1}{c}{ tests } & adsorbers & $\begin{array}{c}\text { organic } \\
\text { solvent }\end{array}$ & $\begin{array}{c}\text { cell-free } \\
\text { media }\end{array}$ & cells \\
Diaion HP20 & $85.3 \pm 1.2$ & & $11.9 \pm 1.4$ & $2.8 \pm 0.8$ \\
$\begin{array}{l}\text { Amberlite } \\
\quad \text { XAD4 }\end{array}$ & $45.4 \pm 2.0$ & & $44.1 \pm 2.2$ & $10.5 \pm 1.1$ \\
Amberlite 200C & $29.5 \pm 1.8$ & & $45.1 \pm 2.1$ & $25.4 \pm 1.3$ \\
$\quad \mathrm{Na}$ & & & & \\
LLPPC & & $80.2 \pm 0.8$ & $15.2 \pm 1.8$ & $4.6 \pm 1.1$ \\
Control $[-]^{a}$ & & & $91.7 \pm 1.8$ & $8.3 \pm 1.1$
\end{tabular}

${ }^{a}$ Negative control cultured without extractants. ${ }^{b}$ Data are the mean of the three replicates with \pm SD.

the Diaion HP20 test improved the (-)-patchoulol recovery ratio by $5.1 \%$ to that of the LLPPC control. The lowest recovery from adsorbers was observed in Amberlite 200C Na (29.5\%), where most of the product was recovered from the cell-free media fraction (45\%) and a considerable amount was recovered from the cell fraction (25\%). The latter adsorber resin was the only ionic-exchange type adsorber (acid cation exchange resin), which was inefficient due to the non-ionic nature of $(-)$-patchoulol.
Cell growth was similar in all of the tested adsorbers (CDW $\sim 1 \mathrm{~g} \mathrm{~L}^{-1}$ and $\mathrm{OD}_{600} \sim 2.1$ ), while the negative control grown without extractants showed the lowest growth from all tests (CDW $0.65 \mathrm{~g} \mathrm{~L}^{-1}$ and $\mathrm{OD}_{600} 0.7$ ) (Figure $5 \mathrm{~b}$ ). The negative control showed the lowest (-)-patchoulol recovery and amount of soluble (-)-patchoulol synthase protein when compared to those of the other tests (Figure S5). This confirms that the application of liquid or solid extractants is required during cultivation; on one hand, to avoid the loss of terpenes by volatilization, and on the other hand, to avoid cell toxicity. Eventually, terpenes with $\log \mathrm{P} \leq 4.5$ could be toxic to E. coli cells since they partition into the cell membrane, causing structural alterations. ${ }^{61}$ Hence, it is plausible that the terpenes produced in our tests, such as (-)-patchoulol (log P 4.4), could be toxic to the cells, as observed for limonene ( $\log$ P 4.4) in E. coli liposomes, ${ }^{62}$ and for linalool ( $\log P$ 2.9) in Corynespora cassiicola. ${ }^{63}$

Diaion HP20 recovered the highest (-)-patchoulol amounts from all adsorber tests with results similar to LLPPC. Likewise, the pore size and pore volume from Diaion HP20 (290 $\AA, 1.3$ $\mathrm{mL} \mathrm{g}^{-1}$ ) were higher than the Amberlite XAD4 (100 $\AA, 0.5 \mathrm{~mL}$ $\mathrm{g}^{-1}$ ), where Diaion HP20 pores were designed to adsorb large molecules like small peptides. This suggests that the adsorption efficiency of (-)-patchoulol is related to the pore size, as demonstrated for the adsorption of other terpenes. ${ }^{64}$ Possibly, large pores facilitate the diffusion of sesquiterpenes inside the resin cavities and improve adsorption efficiency. This idea is supported due to the accordance of our results with other studies, in which Diaion HP20 achieved the highest recovery of the target products, and to a lesser degree, the Amberlite $\mathrm{XAD} 4$; as shown for the recovery of the prodigiosin-like red pigment from Serratia sp. KH-95, ${ }^{65}$ epi-cedrol from recombinant Saccharomyces cerevisiae, ${ }^{66}$ and benzaldehyde and $\mathrm{L}$ phenylalanine from Pycnoporus cinnabarinus. ${ }^{67}$

2.5. Scale-Up to Bioreactors. To improve (-)-patchoulol productivity, the process was scaled-up to $2 \mathrm{~L}$ stirred-tank bioreactors by SLPPC with an internal recovery configuration ( $50 \mathrm{~g} \mathrm{~L}^{-1}$ of the Diaion HP20 inside the vessel). To increase cell growth and the product titer, the fed-batch cultivation was implemented to supply minimal levels of glucose and to avoid overflow metabolism. To circumvent the inclusion body formation of the (-)-patchoulol synthase protein, the early induction $\left(\mathrm{OD}_{600} \sim 5\right)$ was preferred over the late induction 

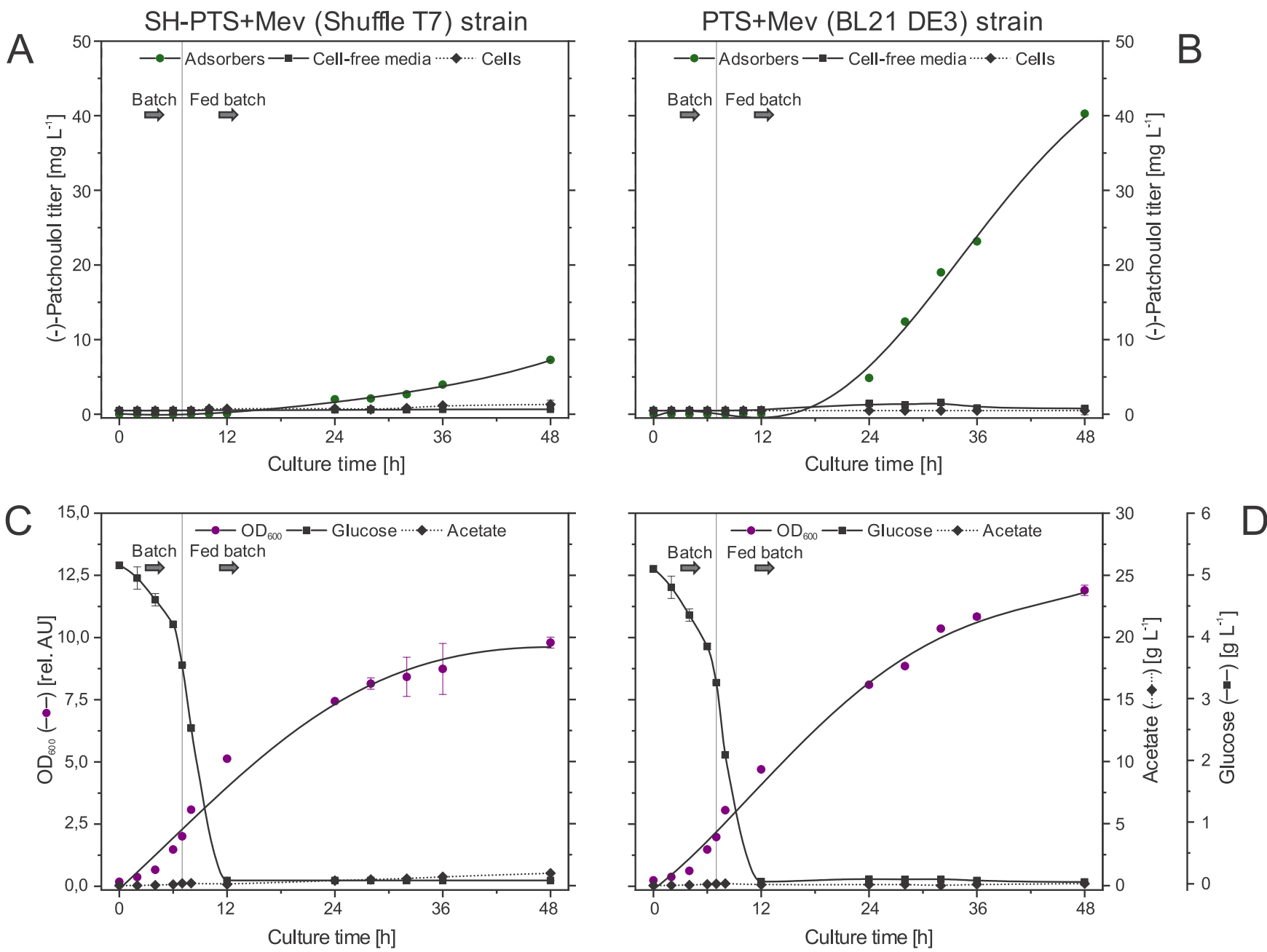

Figure 6. (-)-Patchoulol production in a $2 \mathrm{~L}$ bioreactor from the SH-PTS + Mev (A) and PTS + Mev (B) E. coli strains, represented as the $(-)$-patchoulol titer recovered from adsorbers (green circle filled), cell-free media $(\boldsymbol{\square})$, and cells $(\checkmark)$. Growth kinetics depicted by the optical density $\left(\mathrm{OD}_{600}\right)$ (magenta circle filled), glucose ( $\left.\mathbf{\square}\right)$, and acetate ( $)$ from the SH-PTS + Mev (C) and PTS + Mev (D) E. coli strains. Data are the mean of three sample replicates with SD error bars.

$\left(\mathrm{OD}_{600} \sim 15\right)$. In previous trials, several E. coli B strains were tested at shake flask scale with promising results by the BL21(DE3) (PTS + Mev) and Shuffle (SH-PTS + Mev) strains. Consequently, both were tested at bioreactor scale and cultivated under optimal conditions $\left(20^{\circ} \mathrm{C}, \mathrm{pH} 6.75\right.$, and $\mathrm{ADM}$ medium). For bioreactor cultivations, the ADM medium was supplemented with $5 \mathrm{~g} \mathrm{~L}^{-1}$ glucose for the batch phase and the $\mathrm{pO}_{2}$ was set over $30 \%$, controlled by the stirrer.

For the fermentation of the Shuffle SH-PTS + Mev strain, the glucose was depleted after $12 \mathrm{~h}$ of culture, and the fedbatch stage was initiated by lowering the temperature to $20^{\circ} \mathrm{C}$, feeding the fed-batch medium (ADM medium with $100 \mathrm{~g} \mathrm{~L}^{-1}$ of glucose) and inducing with IPTG. Due to the constant feeding, the cell growth rate was maintained linearly between 12 and $48 \mathrm{~h}$ (Figure 6c). The (-)-patchoulol levels recovered from adsorbers increased after induction, reaching the highest amount at $48 \mathrm{~h}$ of culture with a (-)-patchoulol titer of $7.5 \mathrm{mg}$ $\mathrm{L}^{-1}$ (Figure 6a). As expected, the bioreactor cultivation improved the (-)-patchoulol titer 2.6-fold and yield 2.4-fold when compared to those of the shake flask tests. The (-)-patchoulol recovery ratio from the adsorbers was enhanced up to $93.6 \%$, followed by $5.4 \%$ from cells and $1.0 \%$ from cell-free media, confirming an efficient product recovery from the solid adsorbents.
Fermentation carried out with the BL21(DE3) PTS + Mev strain showed a higher cell growth than the Shuffle SH-PTS + $\mathrm{Mev}$ strain, reaching an $\mathrm{OD}_{600}$ of 11 (Figure 6d). Surprisingly, the BL21(DE3) PTS + Mev strain achieved the highest (-)-patchoulol production from all tests, reaching $40.3 \mathrm{mg} \mathrm{L}^{-1}$ (-)-patchoulol titer at $48 \mathrm{~h}$ of growth, improving the (-)-patchoulol level 14.1-fold, yield 3.9-fold, and productivity 7.1-fold when compared to those of the shake flask tests (Figure 6b).

As an explanation, bioreactors can control $\mathrm{pH}$ values and supply higher levels of oxygen than shake flask cultures, which enhanced the terpene production in microbial platforms. ${ }^{24}$ Besides, fed-batch cultivation is beneficial because it keeps acetate levels at a minimum, reducing the formation of inclusion bodies of terpene synthases, as demonstrated in the production of the sesquiterpene khusimene in E. coli. ${ }^{44}$

The BL21(DE3) PTS + Mev strain obtained the highest recovery ratio of (-)-patchoulol from all tests (adsorbers $99.65 \%$, cell-free media $0.35 \%$, and cells $0.0002 \%$ ), improving the recovery ratio by $17 \%$ when compared to that of the SLPPC at shake flask scale. Possibly, the stronger mixing in bioreactors due to the radial stirring facilitated the adsorption of terpenes when compared to that of the orbital agitation in shake flask experiments. 
The BL21(DE3) PTS + Mev strain significantly improved the (-)-patchoulol titer 5.4-fold, yield 1.6-fold, and productivity 5.4-fold when compared to those of the Shuffle SH-PTS + Mev strain. The latter strain additionally overexpresses the disulfide bond isomerase DsbC chaperone that assists the folding of proteins. Apparently, the DsbC chaperone did not enhance the activity of the overexpressed heterologous proteins, as demonstrated in the low $(-)$-patchoulol levels. Besides, the reduced cell growth observed in the Shuffle SHPTS + Mev strain suggests a higher metabolic burden when compared to the BL21(DE3) PTS + Mev strain due to the overexpression of the DsbC chaperone.

The (-)-patchoulol production from the BL21(DE3) PTS + Mev was similar to that of the CEN.LA100 ${ }^{22}$ and YPH499/ PAT167/MVA442 ${ }^{68}$ yeast strains, which reached maximum (-)-patchoulol titers of 40.9 and $42.1 \mathrm{mg} \mathrm{L}^{-1}$, respectively. Interestingly, the productivity of the PTS + Mev strain (20.2 $\left.\mathrm{mg} \mathrm{L}^{-1} \mathrm{~d}^{-1}\right)$ was higher than these engineered S. cerevisiae strains (8.1 and $8.4 \mathrm{mg} \mathrm{L}^{-1} \mathrm{~d}^{-1}$, respectively). Moreover, the PTS + Mev strain showed higher productivity than the PAT3 C. glutamicum strain $\left(18 \mathrm{mg} \mathrm{L}^{-1} \mathrm{~d}^{-1}\right),{ }^{24}$ resulting in the highest (-)-patchoulol productivity in bacterial systems so far. A possible contributing factor for the enhanced $(-)$-patchoulol productivity is the particular design of the multi-plasmid PTS + $\mathrm{Mev}$ strain, which consists of the $\mathrm{pMev}$ vector for the production of FDP and the pET16b::his-FXa-PTSopt vector for the exclusive production of (-)-patchoulol synthase. Such a strategy increases the overexpression of the terpene synthase when compared to that of single-plasmid strains (one polycistronic vector), improving the levels of terpenes as demonstrated for the production of the sesquiterpene khusimene in E. coli. ${ }^{32}$ The aforementioned yeast and $C$. glutamicum engineered strains used LLPPC with n-dodecane as the liquid extractant, which demonstrated particular issues for the $(-)$-patchoulol recovery, such as emulsion formation and volatilization of $n$-dodecane. On the contrary, the application of SLPPC with polymeric adsorbers avoided such limitations due to the solid polymeric matrix of the Diaion HP20. In consequence, the use of SLPPC is another contributing factor for the efficient recovery of $(-)$-patchoulol in long term fedbatch cultivations, as also demonstrated for the recovery of carvone from the fermentation of Rhodococcus erythropolis DCL14. ${ }^{69}$

\section{CONCLUSIONS}

In this work, we demonstrated the microbial production of patchouli oil sesquiterpenes with a similar product profile and scent than the naturally occurring patchouli oil, as well as new insights into the fermentation and in situ recovery of terpenes. The metabolic engineering of (-)-patchoulol was successfully carried out in E. coli, where the PTS strain produced low amounts of (-)-patchoulol, using the endogenous MEP pathway and the (-)-patchoulol synthase isoform from our previous study. This evidenced a low FDP pool, which was confirmed by overexpressing the MEV pathway in the PTSMev strain, which improved the FDP supply and in turn, the (-)-patchoulol levels.

The fermentation conditions were optimized and enhanced the (-)-patchoulol production 3-fold, where the nitrogen content in the media was a crucial factor to augment the $(-)$ patchoulol production. In addition, the $\mathrm{pH}$ and temperature of culture media had an important effect in the overexpression of soluble (-)-patchoulol synthase protein and (-)-patchoulol production, where $\mathrm{pH} 6.75$ and $20{ }^{\circ} \mathrm{C}$ were found optimal for (-)-patchoulol production.

The SLPPC was studied for the in situ recovery of (-)-patchoulol to avoid the limitations of the LLPPC. The Diaion HP20 demonstrated the highest (-)-patchoulol recovery among all of the tested polymeric adsorbers, suggesting that the large pore size from the adsorbers improves the recovery of (-)-patchoulol.

The application of fed-batch cultivation in bioreactors with the Diaion HP20 improved the (-)-patchoulol productivity 14.1 -fold and recovery ratio by $17 \%$ when compared to those of the shake flask tests. As a result, the use of the Diaion HP20 as the solid extractant reached $99 \%$ of the recovery ratio of (-)-patchoulol, avoiding the problems from LLPPC such as emulsion formation and volatilization.

This study demonstrated the production of patchouli oil sesquiterpenes in E. coli by SLPPC, achieving the highest $(-)$-patchoulol productivity in bacterial systems $\left(20.1 \mathrm{mg} \mathrm{L}^{-1}\right.$ $\left.\mathrm{d}^{-1}\right)$. Moreover, paves the way for further studies in the production of fragrant sesquiterpenes by microbial platforms.

\section{MATERIALS AND METHODS}

4.1. Materials and Chemicals. The chemicals used in this work were of analytical grade. The information of plasmids, strains, and primers are listed in Table S1.

4.2. Metabolic Engineering of the (-)-Patchoulol Pathway. For gene assembly, the GeneArt Seamless cloning \& assembly system (Life Technologies) was carried out. The amplification of plasmids and inserts were conducted with the Q5 HiFi DNA polymerase (New England BioLabs) and oligonucleotides were synthesized by Thermo Scientific. For this study, a (-)-patchoulol synthase isoform "variant 1 " from $P$. cablin was used. The gene was codon-optimized for E. coli and cloned into an expression vector under the control of the T7 promoter, yielding the pET16b::his-FXa-PTSopt plasmid, as described in our previous work. ${ }^{20}$ For the mevalonate pathway, the pBbA5c-MevT(CO)-MBIS (CO, ispA) plasmid (pMev) was used, which was kindly provided by Jay Keasling \& Taek Soon Lee (Addgene plasmid \#35151). This plasmid version includes the E. coli genes (ATOB, IDI, and ISPA) and the codon-optimized genes (HMGS, tHMGR, $M K, P M K$, and $P M D$ ) from $S$. cerevisiae, all under the control of the lacUV5 promoter. Due to its large size $(13 \mathrm{~kb})$, the plasmid was maintained in the NEB $10-\beta$ competent E. coli cells (NEB BioLabs).

For the construction of the PTS and Mev strains, E. coli BL21(DE3) cells were transformed with the pET16b::his-FXaPTSopt and pMev plasmids, respectively. The multi-plasmid PTS + Mev and SH-PTS + Mev strains were built by cotransforming E. coli BL21(DE3) and SHuffle T7 cells, respectively, with both the aforementioned plasmids. The transformation protocol followed the heat shock method as described elsewhere. $^{70}$

4.3. Comparison of the Whole-Cell (-)-Patchoulol Production from Engineered E. coli Strains. Pre-cultures for $E$. coli strains were conducted by inoculating $100 \mu \mathrm{L}$ of glycerol stocks into culture tubes with $5 \mathrm{~mL}$ of lysogeny broth (LB) and grown overnight in orbital agitation at $37{ }^{\circ} \mathrm{C}$ with respective antibiotics. (-)-Patchoulol production cultures were initiated by inoculating $2 \%(\mathrm{v} / \mathrm{v})$ pre-cultures into $500 \mathrm{~mL}$ baffled shake flasks with $50 \mathrm{~mL}$ of defined M9 minimal medium ( $5 \mathrm{~g} \mathrm{~L}^{-1}$ glucose, $\left.\mathrm{pH} 7.5\right)$ and cultured at $150 \mathrm{rpm}$ on a rotary shaker at $37^{\circ} \mathrm{C}$. The induction stage started when the 
culture reached $0.6-0.8 \mathrm{OD}_{600}$, where the temperature was lowered to $20{ }^{\circ} \mathrm{C}, 1 \mathrm{mM}$ IPTG was added, and $5 \mathrm{~mL}$ of isooctane was promptly transferred. For each strain, three independent cultivations were carried out and samples were taken every $24 \mathrm{~h}$ for analytical measurements, for a total cultivation time of $72 \mathrm{~h}$.

4.4. Optimization of Cultivation Conditions. A $2^{2}$ factorial design was conducted to optimize the (-)-patchoulol production of the best performing strain (PTS $+\mathrm{Mev})$. For that, the response variables were the $(-)$-patchoulol titer and yield $\left(\mathrm{Y}_{\mathrm{P} / \mathrm{X}}\right)$ and the studied factors were $\mathrm{pH}$ and temperature. Accordingly, the factor levels were $\mathrm{pH} 6.0,7.5$, and $16,24^{\circ} \mathrm{C}$, with a central point of $\mathrm{pH} 6.75$ and $20{ }^{\circ} \mathrm{C}$. Cultivation of (-)-patchoulol production cultures were performed according to Section 4.3. with the M9 medium ( $5 \mathrm{~g} \mathrm{~L}^{-1}$ glucose) and induced with $0.5 \mathrm{mM}$ IPTG. Samples were taken after $24 \mathrm{~h}$ of culture for respective analytical measurements. Plots and factorial design analysis were carried out with the Minitab 16 software.

4.5. Evaluation of Defined Media. Several defined media were analyzed for the (-)-patchoulol production, comprising the ADM medium, ${ }^{32}$ defined non-inducing broth (DNB), ${ }^{71}$ and the minimal M9 medium, ${ }^{50}$ all with the same amount of glucose $\left(5 \mathrm{~g} \mathrm{~L}^{-1}\right)$. In addition, the terrific broth $(\mathrm{TB})^{70}$ was also analyzed to compare complex and defined media. Tests were carried out similar to the previous section at optimized conditions ( $0.5 \mathrm{mM}$ IPTG, $\mathrm{pH} 6.75$, and $20^{\circ} \mathrm{C}$ ), and samples were analyzed after $24 \mathrm{~h}$ of culture. An analysis of variance (ANOVA) and a Bonferroni mean comparison test were carried out for the response variables: (-)-patchoulol titer, (-)-patchoulol yield $\left(\mathrm{Y}_{\mathrm{P} / \mathrm{X}}\right)$, cell dry weight $(\mathrm{CDW})$, and optical density $\left(\mathrm{OD}_{600}\right)$ and analyzed with the Minitab 16 software with a $95 \%$ confidence level.

4.6. Screening of Adsorbers. To analyze the recovery of (-)-patchoulol from the E. coli cultures, different polymeric adsorbers were screened, including Amberlite XAD4 (Supelco), Amberlite 200C Na (Supelco), and Diaion HP20 (Mitsubishi Chemicals, Japan). Adsorbers were conditioned by washing them subsequently with water, isopropanol, and isooctane. Adsorber tests were carried out with the $\mathrm{ADM}$ medium loaded with $50 \mathrm{~g} \mathrm{~L}^{-1}$ respective adsorbers, following cultivation conditions as in the previous section and taking samples after $24 \mathrm{~h}$ of growth. Two controls were conducted: a LLPPC control with an isooctane overlay and a negative control without extractants. Data analysis was similar to that in the previous section for the response variables: the (-)-patchoulol titer recovered from the adsorber fraction, cell dry weight (CDW), and optical density $\left(\mathrm{OD}_{600}\right)$.

4.7. Scale-Up to Bioreactors. The cultivation was scaledup to $2 \mathrm{~L}$ stirred-tank bioreactors (Biostat A + Sartorius, Germany) with $1.5 \mathrm{~L}$ of working volume and cultivated by SLPPC, using Diaion HP20 adsorbers. Bioreactors were equipped with two rushton impellers and the settings were programmed as follows: Temperature $30{ }^{\circ} \mathrm{C}, \mathrm{pO}_{2}$ over $30 \%$ controlled by a stirrer in a range of $400-700 \mathrm{rpm}, \mathrm{pH} 6.75$ controlled by $1 \mathrm{M} \mathrm{HCl}$ and $25 \%(\mathrm{v} / \mathrm{v})$ ammonia, and an airflow rate of $1.0 \mathrm{vvm}$. Bioreactors were prepared with $1.5 \mathrm{~L}$ of the $\mathrm{ADM}$ medium with $5 \mathrm{~g} \mathrm{~L}^{-1}$ glucose and $50 \mathrm{~g} \mathrm{~L}^{-1}$ conditioned Diaion HP20 adsorbers. To control foam, desmophen (Bayer, Germany) was used as the antifoaming agent.

Batch stage started after inoculating pre-cultures from the PTS + Mev or SH-PTS + Mev E. coli strains, grown in the $\mathrm{ADM}$ medium to an initial $\mathrm{OD}_{600}$ of $\sim 0.5$. When glucose was consumed, the fed-batch stage initiated, where the temperature was decreased to $20{ }^{\circ} \mathrm{C}$, the fed-batch medium ${ }^{44}$ with $100 \mathrm{~g}$ $\mathrm{L}^{-1}$ glucose was fed constantly to the bioreactor and $0.5 \mathrm{mM}$ IPTG was added. Analytic measurements from bioreactor samples included optical density, glucose levels, acetate levels and (-)-patchoulol titer from adsorbers, cell-free media, and cell fractions.

4.8. Analytical Measurements. Kinetic analyses, as well as sample extraction and measurements of (-)-patchoulol synthase protein fractions by sodium dodecyl sulfate polyacrylamide gel electrophoresis (SDS-PAGE) analysis were carried out according to our last work. ${ }^{44}$

4.8.1. GC-FID Measurements. For the quantification of (-)-patchoulol, $1 \mu \mathrm{L}$ of sample was injected into a gas chromatographer equipped with a flame ionizing detector (GC-2010 Plus Shimadzu, Japan). Analyses were run through a $30 \mathrm{~m}$ Zebron ZB-Wax Plus column (0.25 mm I.D. $\times 0.25 \mu \mathrm{m}$ thickness; Phenomenex) in splitless mode with the following oven program: $40{ }^{\circ} \mathrm{C}$ for $20 \mathrm{~s}, 10{ }^{\circ} \mathrm{C}$ per min to $200{ }^{\circ} \mathrm{C}$ ramp, $0.5 \mathrm{~min}$ hold, $30{ }^{\circ} \mathrm{C}$ per min to $230{ }^{\circ} \mathrm{C}$ increase, and $2 \mathrm{~min}$ final hold. Quantification of (-)-patchoulol was calculated with a calibration curve of a commercial standard of (-)-patchoulol.

4.8.2. GC-MS Measurements. Terpene products were identified by analyzing samples with a gas chromatographer coupled with a mass spectra detector (Agilent 7890B system), equipped with a $30 \mathrm{~m}$ VF-WAXms capillary column $(0.25 \mathrm{~mm}$ I.D. $\times 0.25 \mu \mathrm{m}$ thickness, Agilent). Samples of $0.5 \mu \mathrm{L}$ were injected into the device using on-column mode with the following oven program: $40{ }^{\circ} \mathrm{C}$ for $3 \mathrm{~min}, 10{ }^{\circ} \mathrm{C}$ per min to $230{ }^{\circ} \mathrm{C}$ increase and $10 \mathrm{~min}$ final hold. Additional settings included $1 \mathrm{~mL}$ per min of constant gas flow (helium 5.0); 230 ${ }^{\circ} \mathrm{C}$ for the ion source; $150{ }^{\circ} \mathrm{C}$ for the quadrupole, $33-300 \mathrm{~m} / \mathrm{z}$ for the mass scan range, and $70.0 \mathrm{eV}$ for the ionization energy. Identification of terpene products was performed by comparing retention indices and mass spectra of samples with references from the mass spectral NIST 14 database and authentic standards obtained from the patchouli oil (SigmaAldrich W283800), extracted from P. cablin (Blanco) Benth of Indonesia.

\section{ASSOCIATED CONTENT}

\section{Supporting Information}

The Supporting Information is available free of charge at https://pubs.acs.org/doi/10.1021/acsomega.0c04590.

Overexpression of the (-)-patchoulol synthase protein; optimization of induction; information of strains, plasmids, and primers; and mass spectra of terpene products (PDF)

\section{AUTHOR INFORMATION}

\section{Corresponding Author}

Sascha Beutel - Institute of Technical Chemistry, Leibniz University of Hannover, 30167 Hannover, Germany; ○ orcid.org/0000-0002-0983-9748; Phone: +49 511762 2867; Email: beutel@iftc.uni-hannover.de; Fax: +49 511 7623004

\section{Authors}

Francisco Aguilar - Institute of Technical Chemistry, Leibniz University of Hannover, 30167 Hannover, Germany 
Kimia Ekramzadeh - Institute of Technical Chemistry, Leibniz University of Hannover, 30167 Hannover, Germany

Thomas Scheper - Institute of Technical Chemistry, Leibniz University of Hannover, 30167 Hannover, Germany

Complete contact information is available at:

https://pubs.acs.org/10.1021/acsomega.0c04590

\section{Notes}

The authors declare no competing financial interest.

\section{ACKNOWLEDGMENTS}

This work was supported by the PINN program from the Ministry of Science, Technology and Telecommunications of Costa Rica (MICITT). We are grateful for the assistance provided for the product identification by Daniel Sandner and Ulrich Krings from the Institute of Food Chemistry at the Leibniz Hannover University. The publication of this article was funded by the Open Access Publishing Fund of Leibniz Universität Hannover.

\section{REFERENCES}

(1) Allied Market Research. https://www.alliedmarketresearch.com/ cosmetics-market (accessed Apr 21, 2020).

(2) Research and Markets. https://www.researchandmarkets.com/ reports/3275915/world-cosmetics-market-opportunities-and (accessed Apr 22, 2020).

(3) Kusuma, H. S.; Mahfud, M. GC-MS analysis of essential oil of Pogostemon cablin growing in Indonesia extracted by microwaveassisted hydrodistillation. Int. Food Res. J. 2017, 24, 1525-1528.

(4) IndustryARC. https://www.industryarc.com/PressRelease/ 2007/Patchouli-Oil-Market-Research.html (accessed Apr 22, 2020).

(5) Sanganeria, P. Essential Oils Market Report, Spring 2020; Ultra International B. V.: Spijkenisse, 2020.

(6) Swamy, M. K.; Mohanty, S. K.; Sinniah, U. R.; Maniyam, A. Evaluation of patchouli (Pogostemon cablin Benth.) cultivars for growth, yield and quality parameters. J. Essent. Oil-Bear. Plants 2015, $18,826-832$.

(7) Murugan, R.; Livingstone, C. Origin of the name "patchouli" and its history. Curr. Sci. 2010, 99, 1274-1276.

(8) Swamy, M. K.; Sinniah, U. R. Patchouli (Pogostemon cablin Benth.): Botany, agrotechnology and biotechnological aspects. Ind. Crops Prod. 2016, 87, 161-176.

(9) Moyler, D. A. Extraction of Flavours and Fragrances with Compressed $\mathrm{CO}_{2}$. In Extraction of Natural Products Using NearCritical Solvents; King, M. B.; Bott, T. R., Eds.; Springer Science Business Media: Dordrecht, 1993; pp 140-183.

(10) Donelian, A.; Carlson, L. H. C.; Lopes, T. J.; Machado, R. A. F. Comparison of extraction of patchouli (Pogostemon cablin) essential oil with supercritical $\mathrm{CO}_{2}$ and by steam distillation. J. Supercrit. Fluids 2009, 48, 15-20.

(11) Swamy, M. K.; Sinniah, U. R. A comprehensive review on the phytochemical constituents and pharmacological activities of Pogostemon cablin Benth.: An aromatic medicinal plant of industrial importance. Molecules 2015, 20, 8521-8547.

(12) van Beek, T. A.; Joulain, D. The essential oil of patchouli, Pogostemon cablin: A review. Flavour Fragrance J. 2018, 33, 6-51.

(13) Yahya, A.; Yunus, R. M. Influence of sample preparation and extraction time on chemical composition of steam distillation derived patchouli oil. Procedia Eng. 2013, 53, 1-6.

(14) Luo, J. P.; Liu, Y. P.; Feng, Y. F.; Guo, X. L.; Cao, H. Two chemotypes of Pogostemon cablin and influence of region of cultivation and harvesting time on volatile oil composition. Acta Pharm. Sin. 2003, 38, 307-310.

(15) Tholl, D. Biosynthesis and Biological Functions of Terpenoids in Plants. In Advances in Biochemical Engineering/Biotechnology;
Schrader, J.; Bohlmann, J., Eds.; Springer International: Switzerland, 2015; pp 63-106.

(16) Frank, A.; Groll, M. The methylerythritol phosphate pathway to isoprenoids. Chem. Rev. 2017, 117, 5675-5703.

(17) Liao, P.; Hemmerlin, A.; Bach, T. J.; Chye, M. L. The potential of the mevalonate pathway for enhanced isoprenoid production. Biotechnol. Adv. 2016, 34, 697-713.

(18) Boronat, A.; Rodríguez-Concepción, M. Terpenoid Biosynthesis in Prokaryotes. In Biotechnology of Isoprenoids; Schrader, J.; Bohlmann, J., Eds.; Springer International Publishing: Cham, 2015; pp 3-18.

(19) Deguerry, F.; Pastore, L.; Wu, S.; Clark, A.; Chappell, J.; Schalk, M. The diverse sesquiterpene profile of patchouli, Pogostemon cablin is correlated with a limited number of sesquiterpene synthases. Arch. Biochem. Biophys. 2006, 454, 123-136.

(20) Hartwig, S.; Frister, T.; Alemdar, S.; Li, Z.; Krings, U.; Berger, R. G.; Scheper, T.; Beutel, S. Expression, purification and activity assay of a patchoulol synthase cDNA variant fused to thioredoxin in Escherichia coli. Protein Expression Purif. 2014, 97, 61-71.

(21) Asadollahi, M. A.; Maury, J.; Patil, K. R.; Schalk, M.; Clark, A.; Nielsen, J. Enhancing sesquiterpene production in Saccharomyces cerevisiae through in silico driven metabolic engineering. Metab. Eng. 2009, 11, 328-334.

(22) Albertsen, L.; Chen, Y.; Bach, L. S.; Rattleff, S.; Maury, J.; Brix, S.; Nielsen, J.; Mortensen, U. H. Diversion of flux toward sesquiterpene production in Saccharomyces cerevisiae by fusion of host and heterologous enzymes. Appl. Environ. Microbiol. 2011, 77, $1033-1040$

(23) Lauersen, K. J.; Baier, T.; Wichmann, J.; Wördenweber, R.; Mussgnug, J. H.; Hübner, W.; Huser, T.; Kruse, O. Efficient phototrophic production of a high-value sesquiterpenoid from the eukaryotic microalga Chlamydomonas reinhardtii. Metab. Eng. 2016, $38,331-343$.

(24) Henke, N. A.; Wichmann, J.; Baier, T.; Frohwitter, J.; Lauersen, K. J.; Risse, J. M.; Peters-Wendisch, P.; Kruse, O.; Wendisch, V. F. Patchoulol production with metabolically engineered Corynebacterium glutamicum. Genes 2018, 9, 1-15.

(25) Schempp, F. M.; Drummond, L.; Buchhaupt, M.; Schrader, J. Microbial cell factories for the production of terpenoid flavor and fragrance compounds. J. Agric. Food Chem. 2018, 66, 2247-2258.

(26) Vickers, C. E.; Bongers, M.; Liu, Q.; Delatte, T.; Bouwmeester, $\mathrm{H}$. Metabolic engineering of volatile isoprenoids in plants and microbes. Plant Cell Environ. 2014, 37, 1753-1775.

(27) Wang, C.; Liwei, M.; Park, J. B.; Jeong, S. H.; Wei, G.; Wang, Y.; Kim, S. W. Microbial platform for terpenoid production: Escherichia coli and yeast. Front. Microbiol. 2018, 9, 1-8.

(28) Sørensen, H. P.; Mortensen, K. K. Soluble expression of recombinant proteins in the cytoplasm of Escherichia coli. Microb. Cell Fact. 2005, 4, No. 1.

(29) Schewe, H.; Mirata, M. A.; Schrader, J. Bioprocess Engineering for Microbial Synthesis and Conversion of Isoprenoids. In Biotechnology of Isoprenoids. Advances in Biochemical Engineering/ Biotechnology; Schrader, J.; Bohlmann, J., Eds.; Springer: Cham, 2015; pp 251-286.

(30) Dafoe, J. T.; Daugulis, A. J. In situ product removal in fermentation systems: Improved process performance and rational extractant selection. Biotechnol. Lett. 2014, 36, 443-460.

(31) Peralta-Yahya, P. P.; Ouellet, M.; Chan, R.; Mukhopadhyay, A.; Keasling, J. D.; Lee, T. S. Identification and microbial production of a terpene-based advanced biofuel. Nat. Commun. 2011, 2, No. 483.

(32) Aguilar, F.; Scheper, T.; Beutel, S. Modulating the precursor and terpene synthase supply for the whole-cell biocatalytic production of the sesquiterpene $(+)$-zizaene in a pathway engineered $E$. coli. Genes 2019, 10, 478 .

(33) Wang, C.; Yoon, S. H.; Shah, A. A.; Chung, Y. R.; Kim, J. Y.; Choi, E. S.; Keasling, J. D.; Kim, S. W. Farnesol production from Escherichia coli by harnessing the exogenous mevalonate pathway. Biotechnol. Bioeng. 2010, 107, 421-429. 
(34) Withers, S. T.; Gottlieb, S. S.; Lieu, B.; Newman, J. D.; Keasling, J. D. Identification of isopentenol biosynthetic genes from Bacillus subtilis by a screening method based on isoprenoid precursor toxicity. Appl. Environ. Microbiol. 2007, 73, 6277-6283.

(35) Guan, Z.; Breazeale, S. D.; Raetz, C. R. H. Extraction and identification by mass spectrometry of undecaprenyl diphosphateMurNAc-pentapeptide-GlcNAc from Escherichia coli. Anal. Biochem. 2005, 345, 336-339.

(36) Okada, K.; Minehira, M.; Zhu, X.; Suzuki, K.; Nakagawa, T.; Matsuda, H.; Kawamukai, M. The ispB gene encoding octaprenyl diphosphate synthase is essential for growth of Escherichia coli. J. Bacteriol. 1997, 179, 3058-3060.

(37) Nybo, S. E.; Saunder, J.; McCormick, S. Metabolic engineering of Escherichia coli for production of valerenadiene. J. Biotechnol. 2017, $262,60-66$

(38) Yahya, A.; Yunus, R. M. Influence of sample preparation and extraction time on chemical composition of steam distillation derived patchouli oil. Procedia Eng. 2013, 53, 1-6.

(39) Sundaresan, V.; Singh, S. P.; Singh, M.; Shasany, A. K.; Darokar, M. P.; Kalra, A.; Naqvi, A. A. Composition and comparison of essential oils of Pogostemon cablin (Blanco) Benth. (Patchouli) and Pogostemon travancoricus Bedd. var. travancoricus. J. Essent. Oil Res. 2009, 21, 220-222.

(40) Hoffmann, F.; Weber, J.; Rinas, U. Metabolic adaptation of Escherichia coli during temperature-induced recombinant protein production: 1. Readjustment of metabolic enzyme synthesis. Biotechnol. Bioeng. 2002, 80, 313-319.

(41) Christianson, D. W. Structural and chemical biology of terpenoid cyclases. Chem. Rev. 2017, 117, 11570-11648.

(42) Ekramzadeh, K.; Brämer, C.; Frister, T.; Fohrer, J.; Kirschning, A.; Scheper, T.; Beutel, S. Optimization of factors influencing enzyme activity and product selectivity and the role of proton transfer in the catalytic mechanism of patchoulol synthase. Biotechnol. Prog. 2019, 36, $1-11$.

(43) Semra, A.; König, J. C.; Hartwig, S.; Frister, T.; Scheper, T. Bioproduction of $\alpha$-humulene in metabolically engineered Escherichia coli and application in zerumbone synthesis. Engine 2017, 17, 900907.

(44) Aguilar, F.; Scheper, T.; Beutel, S. Improved production and in situ recovery of sesquiterpene (+)-zizaene from metabolicallyengineered E. coli. Molecules 2019, 24, 3356.

(45) Stancik, L.; Stancik, D.; Schmidt, B.; Barnhart, M.; Yoncheva, Y.; Slonczewski, J. pH-dependent expression of periplasmic proteins and amino acid catabolism in Escherichia coli. J. Bacteriol. 2010, 184, 4246-4258.

(46) Wilks, J. C.; Slonczewski, J. L. pH of the cytoplasm and periplasm of Escherichia coli: Rapid measurement by green fluorescent protein fluorimetry. J. Bacteriol. 2007, 189, 5601-5607.

(47) Cao, Y.; Zhang, R.; Liu, W.; Zhao, G.; Niu, W.; Guo, J.; Xian, M.; Liu, H. Manipulation of the precursor supply for high-level production of longifolene by metabolically engineered Escherichia coli. Sci. Rep. 2019, 9, No. 95.

(48) Schalk, M.; Pastore, L.; Mirata, M. A.; Khim, S.; Schouwey, M.; Deguerry, F.; Pineda, V.; Rocci, L.; Daviet, L. Toward a biosynthetic route to sclareol and amber odorants. J. Am. Chem. Soc. 2012, 134, $18900-18903$.

(49) Rodríguez-Aparicio, L. B.; Reglero, A.; Ortiz, A. I.; Luengo, J. M. Effect of physical and chemical conditions on the production of colominic acid by E. coli in defined medium. Appl. Microbiol. Biotechnol. 1988, 27, 474-483.

(50) Miller, J. H. Experiments in Molecular Genetics; Cold Spring Harbor Laboratory Press: New York, 1972.

(51) Martin, V. J. J.; Yoshikuni, Y.; Keasling, J. D. The in vivo synthesis of plant sesquiterpenes by Escherichia coli. Biotechnol. Bioeng. 2001, 75, 497-503.

(52) Martin, V.; Pitera, D.; Withers, S.; Newman, J.; Keasling, J. Engineering a mevalonate pathway in Escherichia coli for production of terpenoids. Nat. Biotechnol. 2003, 21, 796-802.
(53) Boghigian, B. A.; Myint, M.; Wu, J.; Pfeifer, B. A. Simultaneous production and partitioning of heterologous polyketide and isoprenoid natural products in an Escherichia coli two-phase bioprocess. J. Ind. Microbiol. Biotechnol. 2011, 38, 1809-1820.

(54) Newman, J. D.; Marshall, J.; Chang, M.; Nowroozi, F.; Paradise, E.; Pitera, D.; Newman, K. L.; Keasling, J. D. High-level production of amorpha-4,11-Diene in a two-phase partitioning bioreactor of metabolically engineered Escherichia coli. Biotechnol. Bioeng. 2006, 95, 684-691.

(55) Alonso-Gutierrez, J.; Chan, R.; Batt, T. S.; Adams, P. D.; Keasling, J. D.; Petzold, C. J.; Lee, T. S.; Adams, P. D. Metabolic engineering of Escherichia coli for limonene and perillyl alcohol production. Metab. Eng. 2013, 19, 33-41.

(56) Wu, W.; Liu, F.; Davis, R. W. Engineering Escherichia coli for the production of terpene mixture enriched in caryophyllene and caryophyllene alcohol as potential aviation fuel compounds. Metab. Eng. Commun. 2018, 6, 13-21.

(57) Tsuruta, H.; Paddon, C. J.; Eng, D.; Lenihan, J. R.; Horning, T.; Anthony, L. C.; Regentin, R.; Keasling, J. D.; Renninger, N. S.; Newman, J. D. High-level production of amorpha-4,11-Diene, a precursor of the antimalarial agent artemisinin, in Escherichia coli. PLoS One 2009, 4, No. e4489.

(58) van Heeswijk, W. C.; Westerhoff, H. V.; Boogerd, F. C. Nitrogen assimilation in Escherichia coli: Putting molecular data into a systems perspective. Microbiol. Mol. Biol. Rev. 2013, 77, 628-695.

(59) Chubukov, V.; Desmarais, J. J.; Wang, G.; Chan, L. J. G.; Baidoo, E. E. K.; Petzold, C. J.; Keasling, J. D.; Mukhopadhyay, A. Engineering glucose metabolism of Escherichia coli under nitrogen starvation. NPJ Syst. Biol. Appl. 2017, 3, 16035.

(60) Halka, L.; Wichmann, R. Enhanced production and in situ product recovery of fusicocca-2,10(14)-Diene from yeast. Fermentation 2018, 4, 65.

(61) Bruce, L. J.; Daugulis, A. J. Solvent selection strategies for extractive biocatalysis. Biotechnol. Prog. 1991, 7, 116-124.

(62) Sikkema, J.; Bont, J.; Poolman, B. Interactions of cyclic hydrocarbons with biological membranes. J. Biol. Chem. 1994, 269, 8022-8028.

(63) Bormann, S.; Etschmann, M. M. W.; Mirata, M. A.; Schrader, J. Integrated bioprocess for the stereospecific production of linalool oxides from linalool with Corynespora cassiicola DSM 62475. J. Ind. Microbiol. Biotechnol. 2012, 39, 1761-1769.

(64) Krings, U.; Kelch, M.; Berger, R. G. Adsorbents for the recovery of aroma compounds in fermentation processes. J. Chem. Technol. Biotechnol. 1993, 58, 293-299.

(65) Kim, C. H.; Kim, S. W.; Hong, S. I. An integrated fermentationseparation process for the production of red pigment by Serratia $S p$. KH-95. Process Biochem. 1999, 35, 485-490.

(66) Jackson, B. E.; Hart-Wells, E. A.; Matsuda, S. P. T. Metabolic engineering to produce sesquiterpenes in yeast. Org. Lett. 2003, 5, $1629-1632$.

(67) Lomascolo, A.; Lesage-Meessen, L.; Labat, M.; Navarro, D.; Delattre, M.; Asther, M. Enhanced benzaldehyde formation by a monokaryotic strain of Pycnoporus cinnabarinus using a selective solid adsorbent in the culture medium. Can. J. Microbiol. 1999, 45, 653657.

(68) Mitsui, R.; Nishikawa, R.; Yamada, R.; Matsumoto, T.; Ogino, $\mathrm{H}$. Construction of yeast producing patchoulol by global metabolic engineering strategy. Biotechnol. Bioeng. 2020, 117, No. e2935.

(69) Morrish, J. L. E.; Brennan, E. T.; Dry, H. C.; Daugulis, A. J. Enhanced bioproduction of carvone in a two-liquid-phase partitioning bioreactor with a highly hydrophobic biocatalyst. Biotechnol. Bioeng. 2008, 101, 768-775.

(70) Green, M. R.; Sambrook, J. Molecular Cloning: A Laboratory Manual, 4th ed.; Cold Spring Harbor Laboratory Press: New York, 2012.

(71) Li, Z.; Carstensen, B.; Rinas, U. Smart sustainable bottle (SSB) system for E. coli based recombinant protein production. Microb. Cell Fact. 2014, 13, 2-9. 